J. Environ. Sci.

Institute of Environmental Studies and Research - Ain Shams University

\title{
MATHEMATICAL MODELING AND TESTING OF A REVERSED STIRLING CYCLE WATER DISPENSER
}

\author{
Tamr M. Gadelkarem ${ }^{(1)}$; Ahmed M. T. A Eldein Hussin ${ }^{(1)}$; \\ Gamal M. Hennes ${ }^{(1)}$ and Adel A. El-Ehwany ${ }^{(1)}$ \\ 1) Mechanical Power Engineering Department, Faculty of Engineering, Ain \\ Shams University, Cairo, Egypt.
}

\begin{abstract}
One of the most attention-grabbing concerns nowadays is the global warming and environmental impact of different machines. Also, the depletion of the fossil fuel is another important issue which increases the philosophy of developing low power consuming machines. The traditional refrigeration machines, vapor compression machines, have two disadvantages namely: the use of environmental harmful refrigerants and the large amount of input power needed to produce the desired cold. The Stirling cycle is thought to be an alternative for the previously mentioned machines; since it have the ability to be reversed. As the Stirling cycle is reversed, it could be used as refrigerator and heat pumping machine. Several advantages are achieved from using the reversed Stirling cycle including; compact lightweight machines, environment friendly working fluids, quiet machines, fast cool-down technology and the lowest required input power; since the Stirling machines have the highest possible efficiency of the Carnot cycle. A reversed Stirling machine is adopted to be used as a water dispenser for supplying fresh cold/hot water. A schematic diagram for the reversed Stirling dispenser machine was prepared and a mathematical model was set. The different geometrical and operational conditions were optimized to achieve the desired water temperatures at lowest possible input power and obtain acceptable cooling/ heating capacities at reasonable COP. The different machine parts was then manufactured according to the theoretical results and assembled together. The machine was coupled to an electrical motor and tested at different operational conditions. The performance of the machine was evaluated based on the theoretical results. A reasonable cooling/ heating
\end{abstract}


capacities were obtained and subzero temperatures were achieved at no load conditions.

Key words: Stirling refrigerator- Stirling heat pump- water dispenserdrinking water cooler/heater - reversed Stirling cycle

\section{NOMENCLATURE}

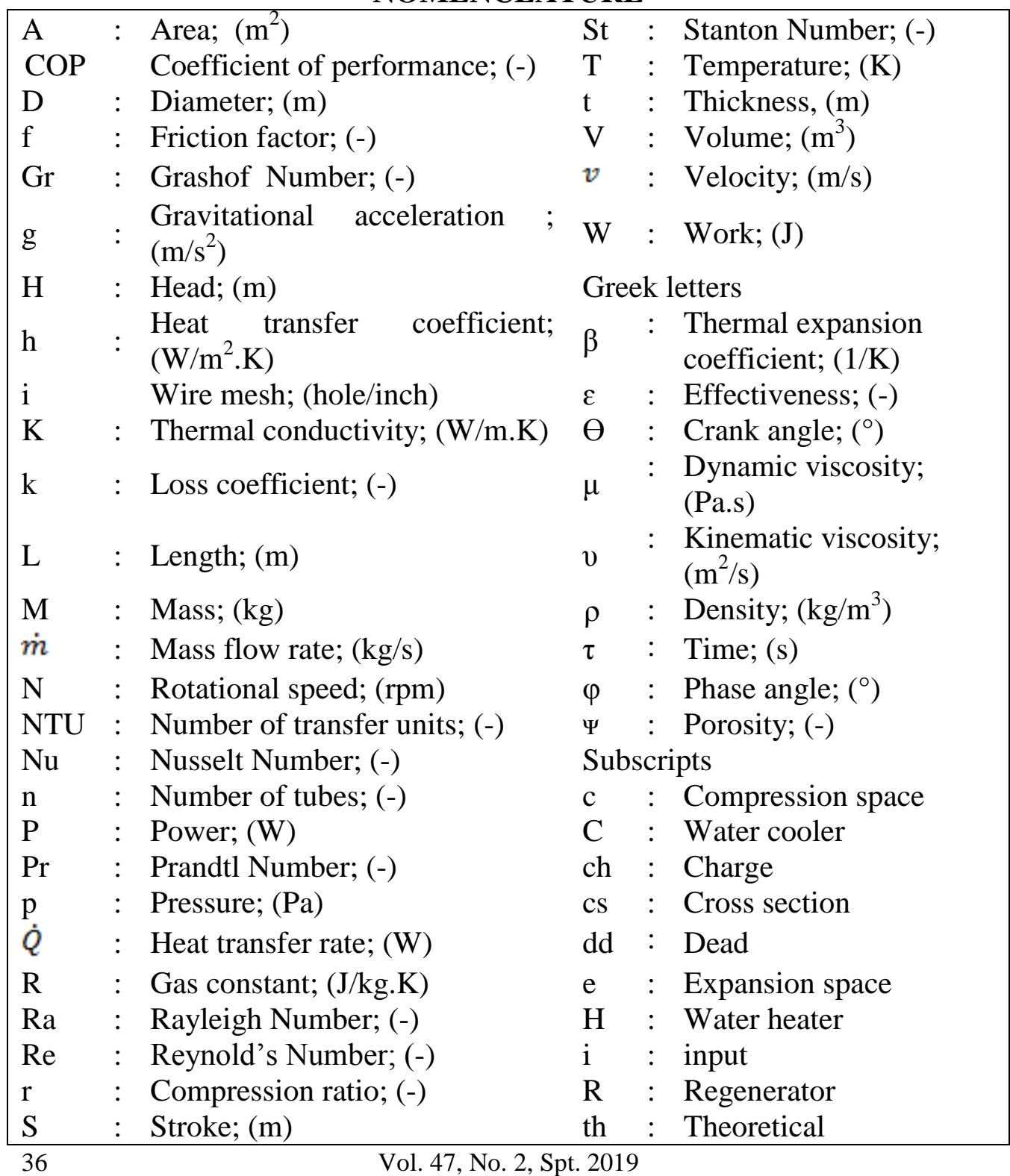


J. Environ. Sci.

Institute of Environmental Studies and Research - Ain Shams University

\section{INTRODUCTION}

The cold/hot water dispenser is one of the essential appliances in this era due to the need for the clean and fresh cold/hot water for life. The most available and conventional cold/hot water dispenser use the vapor compression cycle for producing cold water; while it use an electrical heating element for the hot water demand. The vapor compression cycle could use the new generation of the refrigerants; these refrigerants aids the greenhouse effect (Brown and Domanski, 2014). In addition, the electrical heating element is considered one of the power destructive elements; high power consuming element. On the other hand, the Stirling cycle, which is invented by Robert Stirling in 1815 (Thombare and Verma, 2008), could be reversed and so; gain an input work while absorbing an amount of heat (cooling effect) and releases another amount of heat (heating effect). Hence, the reversed Stirling cycle could be used as refrigerator/heat pumping machine. the reversed Stirling cycle have several advantages including; fast cool down, quiet operation, an eco-friendly working fluid (Ahmadi et. al., 2017) (air, helium, hydrogen and ... etc.) and highest possible efficiency (theoretically Carnot efficiency) and therefore the lowest input power. In the current research, the reversed Stirling cycle was adopted to replace the conventional cold/hot water dispenser in which the absorbed heat is used for water-cooling; whereas the heat rejected is used for water heating with the same amount of input work and without any additional power consumed. The Stirling cycle is a thermodynamic cycle, which consists of two isothermal processes and two isochoric processes. The classical analysis of the Stirling cycle is made by Gustav Schmidt in 1871 (Cheng et. al., 2013). Several research studies were 
done on the Stirling engine to evaluate its performance. Kongtragool and Wonwises, (2006) studied the effect of the dead volumes of the hot, cold and regenerator spaces. His results indicated that the net output power and the efficiency of the engine decrease as the dead volume increases. Puech and Tishkova, (2011) studied the effect of the regenerator dead volume. The theoretical results of Puech indicated that for the perfect regeneration process, the efficiency of the engine does not depend on the regenerator dead volume. However, the regenerator dead volume leads to imperfect regeneration process. Batmaz and Ustun, (2008) studied the performance of a V-type Stirling engine with double heaters. The experimental results show that the engine torque, power and speed increases as the hot side temperature increases. Eldesouki Eid (2009) studied the performance of a beta-type Stirling engine with a regenerative displacer. It concluded that the use of the regenerative displacer has an advantage of decreasing the engine weight. Besides, the engine with the regenerative displacer delivers $20 \%$ more output power. Cinar et. al. (2005) studied the performance of a beta-type Stirling engine under different hot source temperature. The experimental results of Cinar show that the performance of the engine could be increased by increasing the heater inner surfaces and using working fluid of higher thermal conductivity such as helium and hydrogen. El-Ehwany et. al. (2011) studied the performance of an alpha-type Stirling engine by using elbow-bend transposed fluids heat exchangers as heater and cooler. The results show that the elbow-bend heat exchanger decreased the flow losses whereas, the dead volume slightly increased. El-Ehwany show that the net result of using the elbow-bend heat exchanger leads to an increase in engine delivered power at 
higher efficiency levels. On the other hand, great efforts were done on the Stirling refrigerator/ heat pump performance. Le'an et. al. (2009) studied the effect of different operating parameters on the performance of a V-type Stirling refrigerator. The experimental results of Le'an show that increasing the rotational speed and charging pressure leads to increasing the cooling effect up to an optimum values based on the type of the working fluid. Also, Hachem et. al. (2015) studied the performance of an air filled beta-type Stirling refrigerator theoretically and experimentally. The results of this research indicate that the $\mathrm{COP}$ increases by increasing the temperature ratio between the hot and cold sides. The experimental results showed that the thermal losses could diminish the refrigerating effect of the machine. A theoretical analysis on the performance of V-type Stirling refrigerator using different working fluids namely air, helium and hydrogen was performed by Tekin and Ataer, (2010). Their results indicates that the best COP was achieved using the hydrogen working fluid due to the lower pressure drop and the high specific heat of the hydrogen. Another thermodynamic analysis of Vtype Stirling machine filled with air was made by Ataer and Karabulut, (2005). The theoretical results indicated that increasing the heat transfer area and heat transfer coefficient of the hot side leads to an increase in the machine COP. Theoretical and experimental study of a beta-type Stirling cooler with a rhombic drive mechanism was established by Cheng et. al. (2018). The results showed that decreasing the cold side temperature leads to decreasing the machine COP and increasing the heat losses and input power. Also, he showed that the machine performance was reduced due to the rotational speed fluctuations. Eid et. al. (2018) studied the performance of 
beta-type Stirling refrigerator with shell and tube heat exchangers with multiple twisted tapes inserted inside the tubes of the evaporator and condenser. The results showed that the insertion of the twisted tapes increases the performance of the machine.

In the current research, a proposed design of an air filled V-type Stirling cooler/heater used as hot/cold water dispenser was prepared. A theoretical analysis based on the classical Schmidt theory was applied taking into consideration the hydraulic losses inside the different elements of the cycle and the regenerator effectiveness. A spreadsheet computer program was developed to solve the different equations for evaluating the different parameters at each crank angle and the cycle performance was evaluated. A simplest optimization criterion was used to find the optimum geometrical parameters and functional conditions in order to achieve the desired water temperatures $\left(10^{\circ} \mathrm{C}\right.$ cold water temperature and $95^{\circ} \mathrm{C}$ for hot one) and capacities at the lowest possible input work and acceptable COP. The V-type Stirling water dispenser was manufactured according to the dimensions and specification of the theoretical analysis. Then, the water dispenser was tested under various operational parameters and the experimental performance was evaluated.

\section{Proposed Design of the Stirling Water Dispenser And The Theoretical} Analysis:

In this stage of the research, it was decided to make the proposed design as simple as possible in order to simplify the manufacturing of the dispenser. Figure (1) shows the proposed design of the V-type Stirling water dispenser. The V-type Stirling was chosen to make use of the twin cylinder 
reciprocating air compressor, which is commercially available. By uncovering the twin cylinder heads, we obtain the main structure of the Stirling machine that includes expansion and compression spaces with their pistons, connecting rods and crankshaft rotates in the lubricating oil in the crankcase. The crankshaft maintains a fixed phase shift between the pistons by $90^{\circ}$. The rest of Stirling water dispenser components include; 1 - water cooler, which is fitted over the expansion cylinder, 2- water heater, which is fitted over the compression cylinder and 3- a wire mesh regenerator fitted between the water cooler and heater.

The water cooler and water heater were chosen to be shell and tube heat exchangers. The heat absorbed from the water (water-cooling) by the air of the cycle is utilized to achieve an isothermal expansion process at the low pressure whereas; the heat rejected to the water (water heating) from the air of the cycle is also employed to achieve an isothermal compression process at the high pressure. The regenerator, chosen to be of wire mesh layers, work as heat sponge which absorb heat from the air during the first half cycle as the working fluid flows from compression space to the expansion one and then, releases that heat during the next half cycle as the air flows from the expansion to the compression space.

The theoretical analysis is based on the Schmidt theory, which includes the following assumptions:

- The working fluid is considered an ideal gas

- The volume variation of the work space is sinusoidal

- The pressure throughout the system is constant at any instant

- There is no leakage of working fluid from the system 
- The temperature of the compression space and water heater is isothermal

- The temperature of the expansion space and water cooler is isothermal

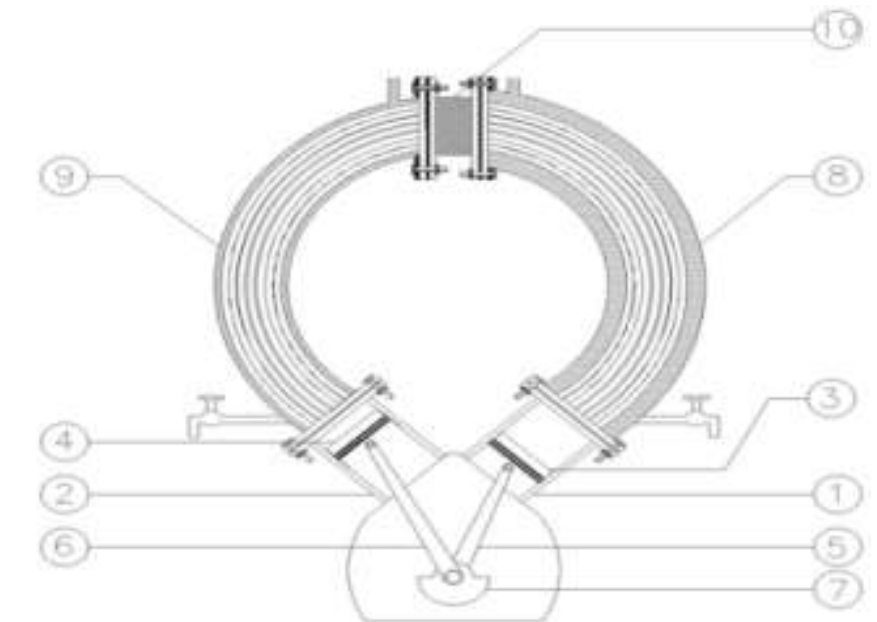
1- Expansion cylinder 7- Drive mechanism
2-Compression cylinder 8- Water Cooler, C
3- Expansion piston 9- Water Heater, $\mathbf{H}$
4-Compression piston 10-Regenerator
5,6 - Connecting rods

Figure (1): the proposed design of the Stirling water dispenser

The volume variation of the compression and expansion spaces were expressed as follows [1]:

$$
\begin{aligned}
& V_{C}=\left(\frac{V_{S C}}{2}\right) \cdot(1+\cos (\theta)) \\
& V_{E}=\left(\frac{V_{S E}}{2}\right) \cdot(1+\cos (\theta+\varphi)) \\
& V_{T}=V_{E}+V_{C}+V_{d d}
\end{aligned}
$$

The compression ratio was calculated by identifying the maximum and minimum volumes 


$$
r=\frac{V_{\max }}{V_{\min }}
$$

The mass of the working fluid was calculated from the charging data as follows:

$$
M_{T}=\left(p_{c h} \cdot V_{\max }\right) /\left(R \cdot T_{c h}\right)
$$

This working fluid mass equals the sum of the working fluid mass in each working space

$$
M_{T}=\frac{p_{c} V_{c}+p_{H} V_{H}}{R T_{H}}+\frac{p_{R} V_{R}}{R T_{R}}+\frac{p_{e} V_{e}+p_{C} V_{C}}{R T_{C}}
$$

Noting that, the regenerator is maintained at logarithmic mean temperature difference

$$
T_{R}=\frac{\left(T_{H}-T_{C}\right)}{\ln \left(\frac{T_{H}}{T_{C}}\right)}
$$

Since the instantaneous pressure throughout the components is the same, then

$$
p=M_{T}\left(R / \sum\left(\frac{V}{T}\right)\right)
$$

Theoretical work input work could be calculated as follows:

$$
\begin{aligned}
& W_{e, t h}=\oint\left(p d V_{e}\right)=\sum\left(p \cdot \Delta V_{e}\right) \\
& W_{c, t h}=\oint\left(p d V_{c}\right)=\sum\left(p \cdot \Delta V_{c}\right) \\
& W_{\text {net }, t h}=W_{\theta_{e}, t h}+W_{c, t h}
\end{aligned}
$$

The average mass flow rate through connections of the dispenser, assuming the positive flow from compression to expansion space, could be calculated as follows: 


$$
\begin{aligned}
& \dot{m}_{c-H}=-\frac{d M_{c}}{d \tau} \\
& \dot{m}_{H-R}=\dot{m}_{c-H}-\frac{d M_{H}}{d \tau} \\
& \dot{m}_{R-C}=\dot{m}_{H-R}-\frac{d M_{R}}{d \tau} \\
& \dot{m}_{C-B}=\dot{m}_{R-C}-\frac{d M_{C}}{d \tau}
\end{aligned}
$$

The mass flow rate of the working through the five different work spaces could be calculated as follows:

$$
\begin{aligned}
& \dot{m}_{C}=\dot{m}_{c-H} / 2 \\
& \dot{m}_{H}=\left(\dot{m}_{c-H}+\dot{m}_{H-R}\right) / 2 \\
& \dot{m}_{R}=\left(\dot{m}_{H-R}+\dot{m}_{R-C}\right) / 2 \\
& \dot{m}_{C}=\left(\dot{m}_{R-C}+\dot{m}_{C-\theta}\right) / 2 \\
& \dot{m}_{\theta}=\dot{m}_{C-\theta} / 2
\end{aligned}
$$

The Reynolds number for the different workspaces was calculated as follows:

$$
\begin{aligned}
& R e_{c}=\frac{4 \dot{m}_{c}}{\pi \mu_{H} D_{c}} \\
& R e_{H}=\frac{4 \dot{m}_{H}}{\pi n_{H} \mu_{H} D_{H}} \\
& R e_{R}=\frac{\dot{m} D_{\text {hy, } R}}{A_{\text {flow, } R} \mu_{\text {mean }}} \\
& \operatorname{Re}_{C}=\frac{4 \dot{m}_{C}}{\pi n_{C} \mu_{C} D_{C}}
\end{aligned}
$$




$$
R e_{e}=\frac{4 \dot{m}_{e}}{\pi \mu_{C} D_{e}}
$$

Consider a periodic flow in the water heater and cooler, the friction factor through inner tubes of water cooler and heater were calculated as follows [17]:

$$
f=(0.79 \ln R e-1.64)^{-2}
$$

Also, the friction factor in the regenerator matrix was calculated as follows[17]:

$$
\begin{array}{ll}
R e_{R} \leq 60 & \log f=1.73-0.93 \log R e_{R} \\
60<R e_{R} \leq 1000 & \log f=0.714-0.365 \log R e_{R} \\
R e_{R}>1000 & \log f=0.015-0.125 \log R e_{R}
\end{array}
$$

Then, the pressure drop across the different space due to the primary losses was calculated. The pressure drop across the compression and expansion spaces were neglected, whereas the pressure drop across the inner tubes of water cooler, water heater and regenerator was calculated as follows:

$\Delta p_{H}=f\left(\frac{8 L_{H}}{\pi^{2} D_{H}{ }^{5}}\right)\left(m_{H} / n_{H}\right)^{2}\left(\frac{R T_{H}}{p}\right)$

$\Delta p_{C}=f\left(\frac{8 L_{C}}{\pi^{2} D_{C}{ }^{5}}\right)\left(m_{C} / n_{C}\right)^{2}\left(\frac{R T_{\text {COLD }}}{p}\right)$

$\Delta p_{R}=f\left(\frac{L_{R}}{2 D_{h y}}\right)\left(\frac{m_{R}^{2}}{A_{\text {flow }}^{2}}\right)\left(\frac{R T_{R}}{p}\right)$

Also, the pressure drop due to the minor flow losses was calculated for each two adjacent spaces as follows: 


$$
\begin{aligned}
& \Delta p_{c-H}=k_{c-H}\left(\frac{8}{\pi^{2} D_{H}^{4}}\right)\left(\frac{\dot{m}_{c-H}^{2}}{n_{H}{ }^{2}}\right)\left(\frac{R T_{H}}{p}\right) \\
& \Delta p_{C-\theta}=k_{C-\theta}\left(\frac{8}{\pi^{2} D_{C}^{4}}\right)\left(\frac{\dot{m}_{C-\theta}{ }^{2}}{n_{C}{ }^{2}}\right)\left(\frac{R T_{C}}{p}\right) \\
& k_{c-H}=\left(1-\frac{n_{H} D_{H}^{2}}{D_{c}{ }^{2}}\right)^{2} \\
& k_{C-\theta}=\left(1-\frac{n_{C} D_{C}{ }^{2}}{D_{e}{ }^{2}}\right)^{2}
\end{aligned}
$$

The flow direction was correctly determined at each crank angle by the sign of the mass flow rate. The maximum and minimum pressures were identified and the actual pressures in the different cycle components were calculated by subtracting the pressure drop from the theoretical cycle pressure at each crank angle according to the flow direction. The actual work, input power, cooling and heating rates and both COP's were calculated as follows [17]:

$$
\begin{aligned}
& W_{e}=\oint\left(p_{e} d V_{e}\right)=\sum\left(p_{e} \cdot \Delta V_{e}\right) \\
& W_{c}=\oint\left(p_{c} d V_{c}\right)=\sum\left(p_{c} \cdot \Delta V_{c}\right) \\
& W_{\text {net }}=W_{e}+W_{c} \\
& P_{\text {in }}=\frac{N \cdot W_{\text {net }}}{60} \\
& \dot{Q}_{\text {cooling }}=\frac{N}{60} \oint_{p_{e}} d V_{e}
\end{aligned}
$$




$$
\begin{aligned}
& \dot{Q}_{\text {heating }}=\frac{N}{60} \oint_{p_{c} d V_{c}} \\
& \text { COP cooling }=\frac{\dot{Q}_{\text {cooling }}}{P_{\text {Cons }}} \\
& C O P_{\text {heating }}=\frac{\dot{Q}_{\text {heating }}}{P_{\text {Cons }}}
\end{aligned}
$$

\section{HEAT TRANSFER CALCULATIONS FOR HEAT EXCHANGERS}

1- The water cooler: According to the proposed design, the water cooler is a curved shell and tube heat exchanger in which the working fluid is flowing inside the inner tubes; whereas the water (to be cooled down) is in the outer shell and in stagnant state surrounds the inner tubes. The heat is extracted from the water to the working fluid to achieve an isothermal expansion process at low pressure. The aim of the research is to obtain the desired water temperature in the shell and so, the water temperature in the outer shell is calculated as follows:

$$
\begin{aligned}
& \dot{Q}_{\text {cooling }}=\frac{N}{60} \oint p_{e} d V_{e}=A_{C_{s i}} h_{C_{e} i}\left(T_{C, s}-T_{C}\right)
\end{aligned}
$$

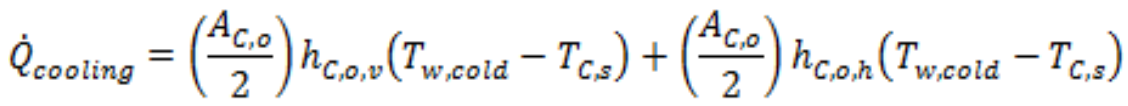

Where, the heat is transferred from the water to the inner tubes surface by free convection. As the tubes have a curved shaped, it was decided to deal with it as half of the tube length is vertically oriented and the other half of the tube length is horizontally oriented. The heat transfer coefficient for the forced convection inside the tubes is calculated as follows: 


$$
\begin{aligned}
& N u_{C_{i} i}=0.023 * R e_{C}{ }^{0.8} * P r_{\varrho T_{C}}{ }^{0.4} \\
& h_{C_{\imath} i}=N u_{C_{i} i} * \frac{K_{\varrho T_{C}}}{D_{C_{\imath} i}}
\end{aligned}
$$

The free convection heat transfer coefficient for the water in the outer shell is calculated as follows:

$$
\begin{aligned}
& G r_{v}=\frac{\left(g \beta\left(T_{w_{i} \text { cold }}-T_{C, s}\right)\left(\frac{L_{C}}{2}\right)^{3}\right)}{(v)^{2}} \\
& R a_{v}=G r_{v} P r \\
& N u_{v}=\left(0.825+\frac{0.387 R a_{v}^{\frac{1}{6}}}{\left(1+\left(\frac{0.492}{P r}\right)^{\frac{9}{16}}\right)^{\frac{8}{27}}}\right)^{2} \\
& h_{C_{\imath}, o_{v} v}=\frac{N u_{v} K}{\left(L_{C} / 2\right)} \\
& G r_{h}=\frac{\left(g \beta\left(T_{w_{i} \text { cold }}-T_{C_{s} s}\right)\left(D_{C_{s} o}\right)^{3}\right)}{(v)^{2}} \\
& R a_{h}=G r_{h} P r \\
& N u_{h}=\left(0.6+\frac{0.387 R a_{h}^{\frac{1}{6}}}{\left(1+\left(\frac{0.559}{P r}\right)^{\frac{9}{16}}\right)^{\frac{8}{27}}}\right)^{2}
\end{aligned}
$$




$$
h_{C, o, h}=\frac{N u_{h} K}{D_{C_{i} o}}
$$

Hence, the cold water temperature was identified.

2- The water Heater For symmetry, the water heater has the same shape of the water cooler. Also, the same procedure was followed to obtain the hot water temperature.

$$
\begin{aligned}
& \dot{Q}_{\text {heating }}=\frac{N}{60} \oint p_{c} d V_{c}=A_{H, i} h_{H, i}\left(T_{H, s}-T_{H}\right) \\
& \dot{Q}_{h \text { eating }}=\left(\frac{A_{H, o}}{2}\right) h_{H, o, v}\left(T_{w, h o t}-T_{H, s}\right)+\left(\frac{A_{H, o}}{2}\right) h_{H, o, h}\left(T_{w, h o t}-T_{H, s}\right) \\
& N u_{H, i}=0.023 * \operatorname{Re}_{H}^{0.8} * P r_{\varrho T_{H}}^{0.3} \\
& h_{H, i}=N u_{H, i} * \frac{K_{@ T_{H}}}{D_{H, i}}
\end{aligned}
$$

The same correlations for free convection of the water in the shell side were used identically. Hence, the hot water temperature could be identified.

3- The regenerator: The regenerator is a type of heat exchangers that absorbs the heat from the working fluid during the first half cycle and releases that heat again to the working fluid during the next half cycle. It consists of successive layers of wire mesh and has a square cross-sectional area; whereas the length was optimized as will be shown in the optimization section. The number of wire mesh layers is dependent on the thickness of the regenerator and wire thickness. Four different configurations of the regenerator were suggested for obtaining the best performance as follows: 


\begin{tabular}{|c|c|c|}
\hline \hline Regenerator & Wire mesh, i (Hole/inch) & Wire diameter; $\mathbf{D}_{\text {wire }}(\mathbf{m m})$ \\
\hline \hline R1 & 20 & 0.2 \\
\hline R2 & 40 & 0.18 \\
\hline R3 & 50 & 0.15 \\
\hline R4 & 100 & 0.1 \\
\hline
\end{tabular}

The porosity of the wire mesh is calculated as follows:

$$
\Psi=1-\left[\frac{\pi}{4} \times \frac{1000}{25.4} \times i \times D_{\text {wire }}\right]
$$

And the hydraulic diameter of the regenerator is calculated as:

$$
D_{\text {hy }}=\left(\frac{\Psi}{1-\Psi}\right) \times D_{\text {wire }}
$$

The regenerator effectiveness is calculated as follows:

$$
\begin{aligned}
& S t_{R}=\left(\frac{0.595}{R e^{0.4} \times P r^{0.667}}\right)_{R} \\
& N T U_{R}=2 \times \overline{S t_{R}} \times \frac{t_{R}}{D_{h y}} \\
& \varepsilon=\frac{N T U_{R}}{1+N T U_{R}}
\end{aligned}
$$

Optimization: A simple optimization technique was used to found the optimum dimensions and specifications of the heat exchangers namely: the water cooler, water heater and regenerator. Also, it was used to found the optimum operating conditions such as the charging pressure and the rotational speed. In the used computer program, an initial dimensions and operational conditions were applied. The optimization process aims at finding the optimum value of certain parameter to achieve the desired water temperatures, cooling and heating capacities at the lowest possible input power and reasonable value of COP. In this optimization technique, the 
J. Environ. Sci.

Institute of Environmental Studies and Research - Ain Shams University

parameter to be optimized was changed through certain values; whereas the other parameters remain unchanged. As changing the parameter to be optimized, the water temperatures were changed continuously and hence, changing the cold and hot working fluid temperatures until achieving the desired water temperatures and recording the values of input power, cooling rate, heating rate and both COP's. Through the previously recorded values of the performance, the optimum parameter value was selected. Table (2) shows the dimensions and specifications of the different dimensional parameters of the machine. The operational conditions were also optimized as will be discussed later in the results and discussion section. 
Table (1): Stirling water dispenser specifications and dimensions

\begin{tabular}{|c|c|c|}
\hline Parameter & Value & State \\
\hline \multicolumn{3}{|l|}{ The reciprocating air compressor } \\
\hline Diameter of compression space, $D_{c}$ & $90 \mathrm{~mm}$ & \multirow{5}{*}{$\begin{array}{l}\text { Not optimized- } \\
\text { Dimensions based on the } \\
\text { commercially available unit }\end{array}$} \\
\hline Diameter of expansion space, $D_{e}$ & $90 \mathrm{~mm}$ & \\
\hline Stroke of compression space, $S_{c}$ & $70 \mathrm{~mm}$ & \\
\hline Stroke of expansion space, $S_{e}$ & $70 \mathrm{~mm}$ & \\
\hline $\begin{array}{l}\text { Phase shift between expansion and } \\
\text { compression pistons, } \varphi\end{array}$ & $90^{\circ}$ & \\
\hline \multicolumn{3}{|l|}{ The water cooler } \\
\hline Diameter of inner tubes, $\mathrm{D}_{\mathrm{C}}$ & $10 \mathrm{~mm}$ & Optimized \\
\hline Length of inner tubes, LC & $650 \mathrm{~mm}$ & Optimized \\
\hline Number of inner tubes, $n_{C}$ & 12 tubes & Optimized \\
\hline Shell diameter, $\mathrm{D}_{\mathrm{C}, \text { shell }}$ & $130 \mathrm{~mm}$ & Based on design capacity \\
\hline Water capacity & 5 litres & Based on design capacity \\
\hline \multicolumn{3}{|l|}{ The water heater } \\
\hline Diameter of inner tubes, $\mathrm{D}_{\mathrm{H}}$ & $10 \mathrm{~mm}$ & Optimized \\
\hline Length of inner tubes, $\mathrm{L}_{\mathrm{H}}$ & $650 \mathrm{~mm}$ & Optimized \\
\hline Number of inner tubes, $n_{H}$ & 12 tubes & Optimized \\
\hline Shell diameter, $\mathrm{D}_{\mathrm{H}, \text { shell }}$ & $90 \mathrm{~mm}$ & Based on design capacity \\
\hline Water capacity & 2.5 litres & Based on design capacity \\
\hline \multicolumn{3}{|l|}{ The regenerator } \\
\hline Square cross-section & $\begin{array}{l}90 \mathrm{~mm} x \\
90 \mathrm{~mm}\end{array}$ & Based on the design \\
\hline Regenerator thickness, $t_{R}$ & $45 \mathrm{~mm}$ & Optimized \\
\hline Regenerator wire mesh ( hole/inch) & 20 & Optimized \\
\hline Regenerator wire diameter, $\mathrm{D}_{\mathrm{w}}$ & $0.2 \mathrm{~mm}$ & Optimized \\
\hline Packing factor & $75 \%$ & \\
\hline
\end{tabular}

\section{THE EXPERIMENTAL MACHINE AND INSTRUMENTATIONS:}

The different Stirling water dispenser (the water cooler, the water heater and regenerator) were manufactured according to the specifications and dimensions of the theoretical analysis, which were mentioned in table (1). Figure (2) shows a photograph of the water dispenser including the different components. The dispenser was fixed on a base and coupled to a three phase 
electrical motor through a pulley and belt. The pulley offers two different rotational speed namely 470 and $380 \mathrm{rpm}$. The water temperatures in the cold and hot shells of the heat exchangers were measured using two calibrated ktype thermocouples of $\pm 0.1^{\circ} \mathrm{C}$ accuracy. The charging pressure was measured using a calibrated bourdon tube gauge of \pm 0.1 bar accuracy, which was fixed into a tap in the regenerator casing. The input power was measured through measuring the line current of the three phase motor by a high accuracy clamp meter of $\pm 2 \%+5$ in the range of $40 \mathrm{~A}$. The rotational speed of the machine was measured using a high accuracy optical laser tachometer of $\pm 0.04 \%+2$ in the range of $0-999 \mathrm{rpm}$.

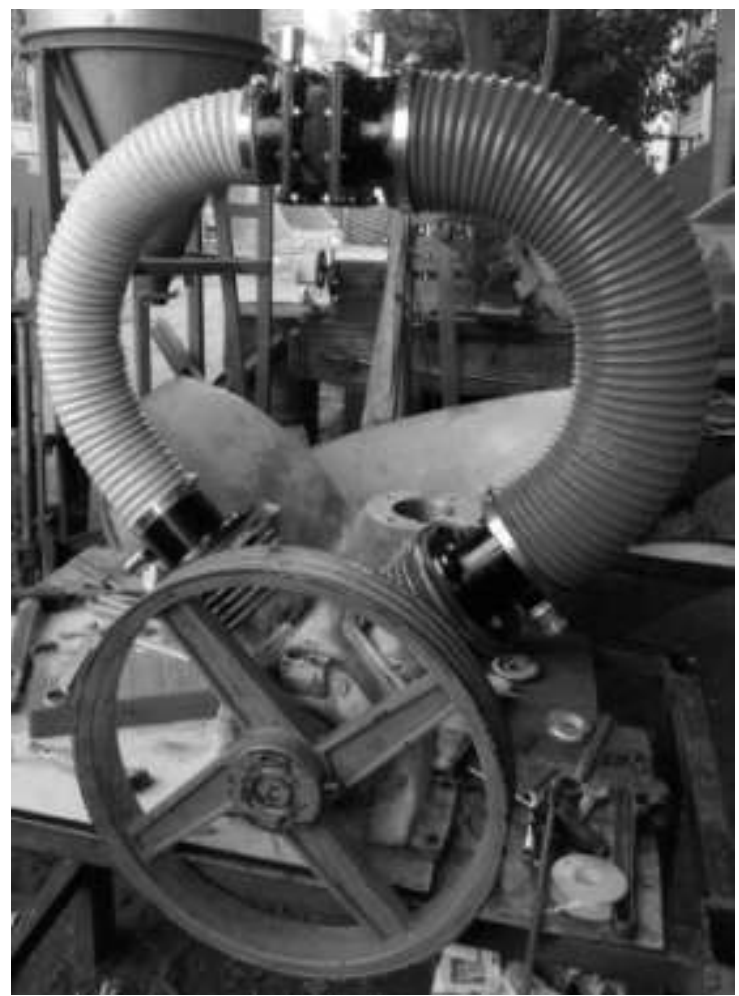

Figure (2): A photograph of the Stirling water dispenser Vol. 47, No. 2, Spt. 2019 


\section{RESULTS AND DISCUSSION}

The Stirling water dispenser was run and tested at two different charging pressures and two different rotational speeds and the performance of the machine was evaluated and compared with the theoretical results.

Effect of the charging pressure: Figure (3) shows the cold and hot water temperatures versus the running time of the machine at constant rotational speed of $470 \mathrm{rpm}$ and two different charging pressures of 3.5 and 4.8 bar. The figure shows that at 3.5 bar charging pressure the cold water temperature (5 liters $)$ decreased from $25^{\circ} \mathrm{C}$ to $15^{\circ} \mathrm{C}$ in about 25 minutes of running $\left(\Delta \mathrm{T}=10^{\circ}\right.$ C) and then remained constant whereas; at 4.8 bar the cold water temperature decreased from $20^{\circ} \mathrm{C}$ to $7.3^{\circ} \mathrm{C}$ in 25 minutes running time $\left(\Delta \mathrm{T}=12.7^{\circ} \mathrm{C}\right)$. On the other hand, the hot water temperature (2.5 liters) increased from $25^{\circ} \mathrm{C}$ to about $77.5^{\circ} \mathrm{C}\left(\Delta \mathrm{T}=52.5^{\circ} \mathrm{C}\right)$ at 3.5 bar whereas; it increased from $20^{\circ} \mathrm{C}$ to $87.5^{\circ} \mathrm{C}\left(\Delta \mathrm{T}=67.5^{\circ} \mathrm{C}\right)$ at 4.8 bar for 25 minutes of running. The previous results indicate that the cooling and the heating capacities of the machines increases by increasing the charging pressure which is in agreement with the theoretical results and results of Hachem et. al. (2015) and Cheng et. al. (2018). 


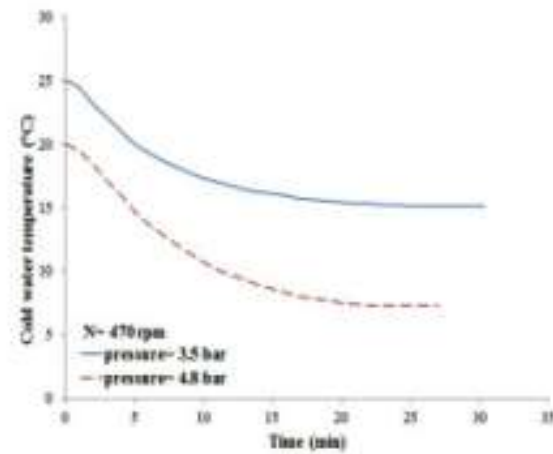

(a)

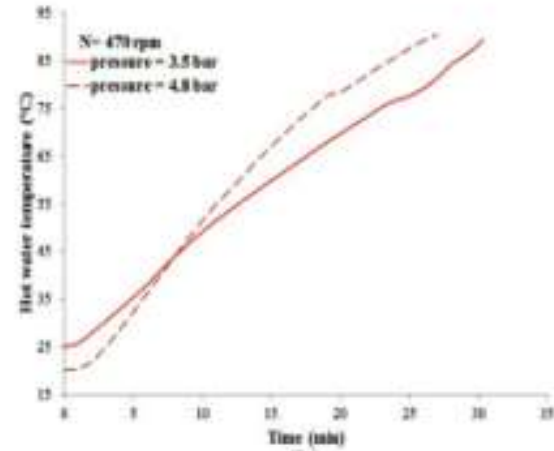

(b)

Figure (3): Cold and hot water temperatures versus running time at different charging pressures

Figure (4) (a) shows the theoretical and experimental relations between the input power and the charging pressure. The theoretical results show that the input power increases nearly linearly as the charging increases, in agreement with $\mathrm{Li}$ and Grosu, (2017). Also, the experimental results show the same behavior. The deviation between the theoretical and the experimental results was due to the mechanical friction of the machine, which was not evaluated in the theoretical analysis. The results show that the deviation between the theoretical and experimental input power increases as the charging pressure increases. Figure (4) (b) shows the theoretical and experimental relations between the cooling and heating powers versus the charging pressure at constant rotational speed. The theoretical results show that the cooling and heating capacities are increases as increases the charging pressure. This occurs due to the increased input power and the increases mass of the working fluid. On the other hand, the experimental results show the increase of the cooling and heating powers by increasing the charging pressure. The difference between the theoretical and experimental 
results was found due to the several thermal losses, which are not calculated in the theoretical analysis. Moreover, the thermal losses increases as the pressure increases due to the higher temperature achieved at the hot side and the colder one achieved at the cold side, which increases the heat transfer from the hot side to the cold side of the regenerator as increasing the running time. The heat losses from the hot end to the cold end of the regenerator leads to the stability of the cold water temperature after 25 minutes of running time in figure (3), in agreement with Le'an et. al.(2009).

Figure (5) shows the theoretical and experimental COP's versus the charging pressure. The theoretical result show that the COP slightly increases as the pressure increases up to 2 bar and then slightly decreases. The experimental results show the same trend as the pressure increases from 3.5 to 4.8 bar. The COP decreases as the pressure increases due to the increases of the thermal losses as the charging pressure increases. The increase of the input power as the charging pressure increases is another reason for the $\mathrm{COP}$ slightly decreases as the pressure increases.

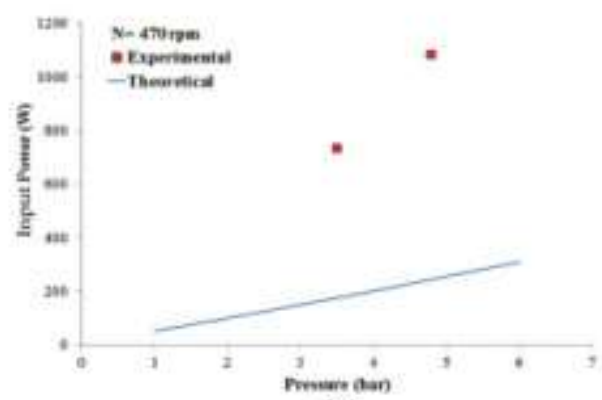

(a)

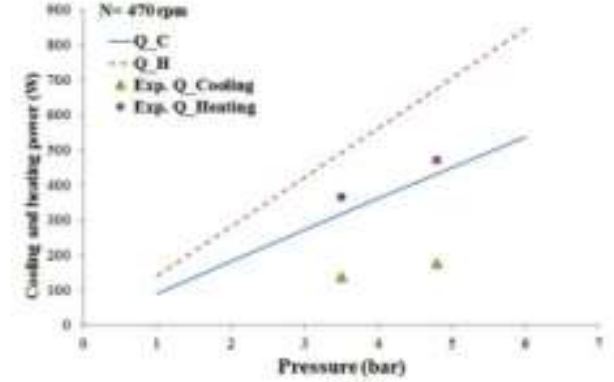

(b)

Figure (4): Input power, cooling and heating powers versus the charging pressure and constant rotational speed 
J. Environ. Sci.

Institute of Environmental Studies and Research - Ain Shams University

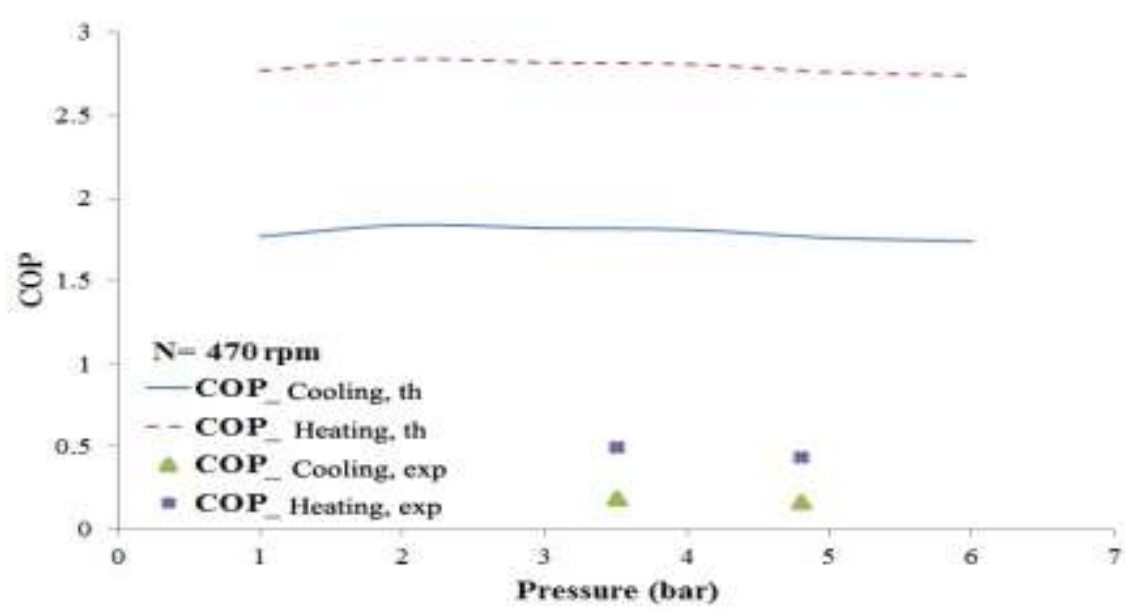

Figure (5): Theoretical and experimental COP's versus the charging pressure and constant rotational speed

Effect of the rotational speed: Figure (6) shows the cold and hot water temperatures versus the running time of the dispenser at constant charging pressure 4.8 bar and two different rotational speeds namely 380 and $470 \mathrm{rpm}$. The results show that the cold water temperature decreases from $19^{\circ} \mathrm{C}$ to $6^{\circ}$ $\mathrm{C}\left(\Delta \mathrm{T}=13^{\circ} \mathrm{C}\right)$ at $380 \mathrm{rpm}$; whereas it decreases from $20^{\circ} \mathrm{C}$ to $7.3^{\circ} \mathrm{C}$ $\left(\Delta \mathrm{T}=12.7^{\circ} \mathrm{C}\right)$ at $470 \mathrm{rpm}$ for 25 minutes of machine running. The results show that the cooling capacity was slightly decreased as the rotational speed changed from 380 to $470 \mathrm{rpm}$. This result implies that the thermal losses increase as the rotational speed increases and hence, a lower temperature was achieved at the lower rotational speed. On the other hand, the hot water temperature increased from $19^{\circ} \mathrm{C}$ to $76.8^{\circ} \mathrm{C}\left(\Delta \mathrm{T}=57.8^{\circ} \mathrm{C}\right)$ at $380 \mathrm{rpm}$; whereas it increased from $20^{\circ} \mathrm{C}$ to $87.5^{\circ} \mathrm{C}\left(\Delta \mathrm{T}=67.5^{\circ} \mathrm{C}\right)$ at $470 \mathrm{rpm}$ for 25 
minutes of running. The result show an increase in the heating power as the rotational speed increases.

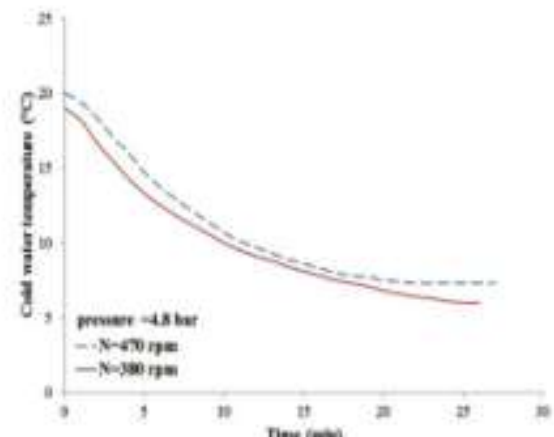

(a)

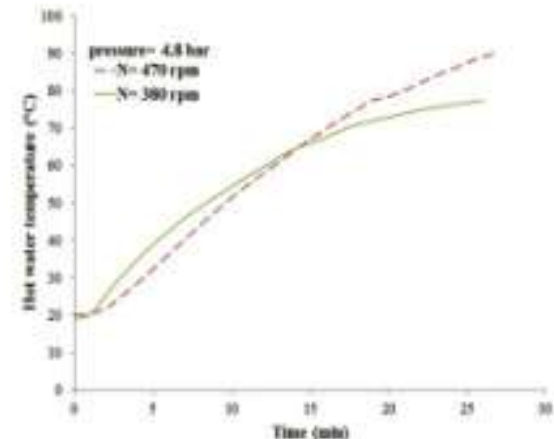

(b)

Figure (6): Cold and hot water temperatures versus running time at different rotational speeds

Figure (7) (a) shows the theoretical and experimental input power versus the rotational speed at constant charging pressure. The theoretical results show that input power increases by increasing the rotational speed, in agreement with $\mathrm{Li}$ and Grosu, (2017). The experimental input power increases as the rotational speed, which is in agreement with the theoretical results. The deviation between the experimental and theoretical input powers was found mainly due to the mechanical frictional losses, which is not taken into consideration in the theoretical analysis. The results show that the mechanical friction losses increases by increasing the rotational speed. Figure (7) (b) shows the theoretical and experimental cooling and heating capacities versus the rotational speed at constant charging pressure of 4.8 bar. The theoretical results show that the cooling and heating capacities increase as the rotational speed increases, in agreement with Batooei and Keshavarz, (2018). 
Besides, the experimental results show that cooling capacity was slightly decreased as the rotational speed increases. This happens due to the increase of the thermal and mechanical losses, which is converted into heat, by increasing the rotational speed. Conversely, the experimental heating capacity increases by increasing the rotational speed. The difference between the theoretical and experimental results is mainly due to the losses, which is not calculated in the theoretical analysis.

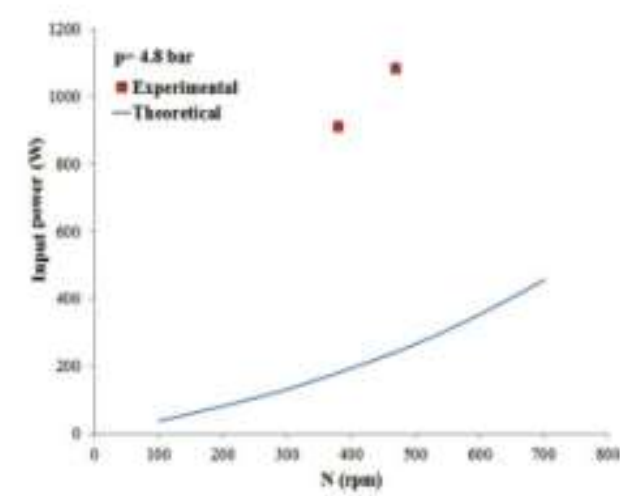

(a)

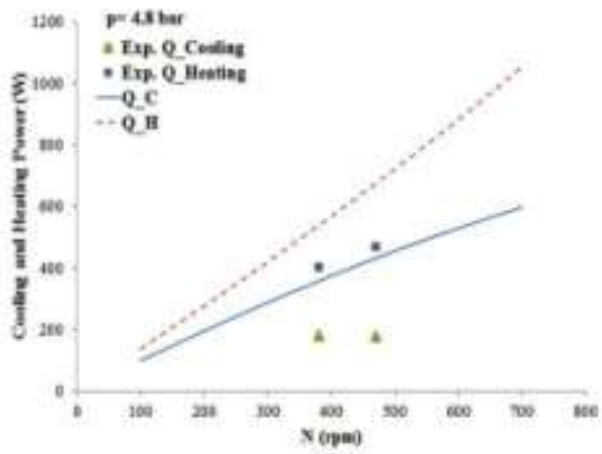

(b)

Figure (7): Input power, cooling and heating powers versus the rotational speed and constant charging pressure

Figure (8) shows the theoretical and experimental COP's versus the rotational speed and constant charging pressure of 4.8 bar. The results show that the COP decreases as the rotational speed increases. This occurs due to the higher increase in the input power than the cooling and heating capacities. Also, the experimental results show a slight decrease in the COP by increasing the rotational speed. 


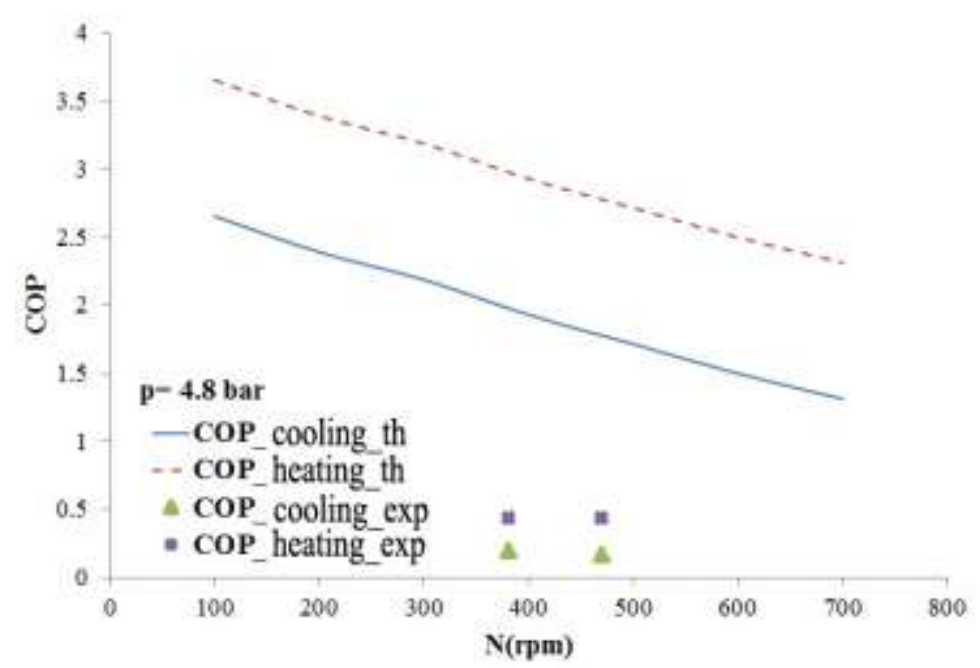

Figure (8): Theoretical and experimental COP's versus the rotational speed and constant charging pressure

No load test: The Stirling water dispenser was tested at the conditions of 380 rpm, 4.8 bar charging pressure and no load at the cold side whereas; the hot side was approximately maintained at $35^{\circ} \mathrm{C}$. At the mentioned conditions, the temperature of the cold side tubes decreased from $16^{\circ} \mathrm{C}$ to $0^{\circ} \mathrm{C}$ in less than 1 minute; whereas it decreased to about $-11^{\circ} \mathrm{C}$ in 6 minutes. Figure (9) shows the formation of frost on the inner tubes of the water cooler at the no load test. 


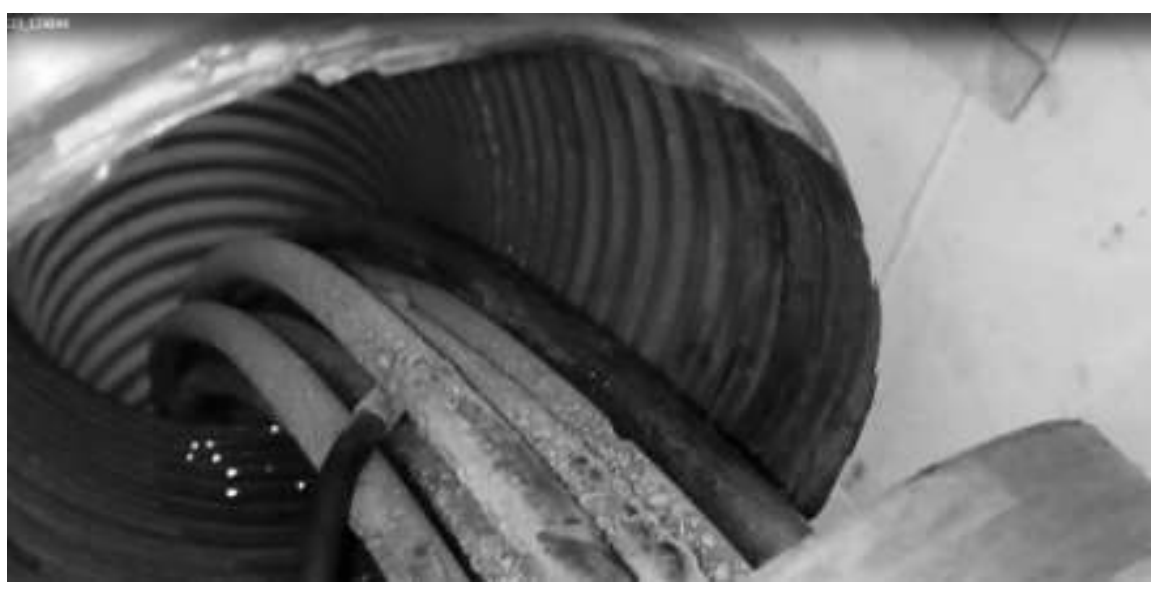

Figure (9): Frost formation on the inner tubes of the water cooler at no load test

\section{Comparison between the Present Work and Some of the Previous Work:}

The following table (2) offers a comparison of the performance of the present water dispenser, which mainly based on the reversed Stirling cycle and some of the previously Stirling coolers in the literature. The comparison is mainly based on the input power, cooling capacity and COP. The table mentions the each machine configuration, the working fluid and the operating conditions.

Table (2): comparison between the present Stirling dispenser and some of the previous ones

\begin{tabular}{||c|c|c|c|c|c|c|c|c||}
\hline \hline Conf & $\begin{array}{c}\text { Working } \\
\text { fluid }\end{array}$ & $\begin{array}{c}\mathbf{p} \\
\text { bar }\end{array}$ & $\begin{array}{c}\mathbf{N} \\
\mathbf{r p m}\end{array}$ & $\begin{array}{c}\mathbf{Q}_{\text {cooling }} \\
\mathbf{W}\end{array}$ & $\begin{array}{c}\mathbf{Q}_{\text {heating }} \\
\mathbf{W}\end{array}$ & $\begin{array}{c}\text { COP } \\
\text { cooling }\end{array}$ & $\begin{array}{c}\mathbf{C O P}_{\mathbf{h}} \\
\text { eating }\end{array}$ \\
\hline \hline Present & Alpha & Air & 4.8 & 380 & 182 & 403 & 0.2 & 0.45 \\
\hline $\begin{array}{c}\text { Batooei } \text { et. al. } \\
(2018)\end{array}$ & $\begin{array}{c}\text { Gam } \\
\text { ma }\end{array}$ & Air & 6 & 500 & 70 & - & 0.095 & - \\
\hline $\begin{array}{c}\text { Cheng } \text { et.al. } \\
(2018)\end{array}$ & Beta & He & 4 & 1000 & 8 & - & 0.07 & - \\
\hline $\begin{array}{c}\text { Hachem } \text { et.al. } \\
(2015)\end{array}$ & Beta & Air & 2 & 132 & $\begin{array}{c}\text { Not } \\
\text { given }\end{array}$ & - & 0.47 & - \\
\hline $\begin{array}{c}\text { Le'an } \text { et.al. } \\
(2009)\end{array}$ & Alpha & He & 10 & 900 & 85 & - & 1 & - \\
\hline
\end{tabular}




\section{CONCLUSIONS}

In the present study, a reversed Stirling water dispenser was proposed for using as a cold/hot water dispenser. A theoretical analysis based on Schmidt theory was applied taking into consideration the effect of the dead volume and the regenerator effectiveness. An optimization technique was used find the optimum geometrical parameters and the operational conditions of the Stirling dispenser. The dispenser was manufactured and tested at two different charging pressures and rotational speeds. Based on the experimental results, it could be concluded that:

- The cooling and heating capacities depend strongly on the charging pressure.

- The rotational speed has a great effect on the mechanical and thermal losses.

- Increasing the rotational speed deteriorates the COP of the machine.

- The input power depends mainly on the charging pressure and the rotational speed.

- Enhancing the mechanical friction leads to decreasing the input power.

- The thermal losses must be eliminated to achieve a higher cooling and heating capacities and obtaining the best COP.

- A higher sub-zero temperatures could be easily achieved from the reversed Stirling machines.

- The reversed Stirling cycle machines could be used efficiently for cooling/heating applications. 


\section{REFERENCES}

Brown, J. S. and Domanski, P. A. (2014): Review of alternative cooling technologies, Applied thermal engineering, 64: 252-262.

Thombare, D. G. and Verma, S. K. (2008): Technological development in the Stirling cycle engines, Renewable and sustainable energy reviews, 12: $1-38$.

Ahmadi, M. H.; Ahmadi, M. A. and Pourfayaz, F. (2017): Thermal models for analysis of performance of Stirling engine: A review, Renewable and sustainable energy reviews, 68: 168-184.

Cheng, C. H.; Yang, H. S. and Keong, L. (2013): Theoretical and experimental study of a $300 \mathrm{~W}$ beta-type Stirling engine, Energy, 59: 590-599.

Kongtragool, B. and Wongwises, S. (2006): Thermodynamic analysis of a Stirling engine including dead volumes of hot space, cold space and regenerator, Renewable energy, 31: 345-359.

Puech, P. and Tishkova, V. (2011): Thermodynamic analysis of a Stirling engine including regenerator dead volume, Renewable energy, 36: 872-878.

Batmaz, I. and Ustun, S. (2008): Design and manufacturing of V-type Stirling engine with double heaters, Applied energy, 85: 1041-1049.

Eid, E. (2009): Performance of a beta-configuration heat engine having a regenerative displacer, Renewable energy, 34: 2404-2413.

Cinar, C.; Yecesu, S.; Topgul, T. and Okur, M. (2005): Beta-type Stirling engine operating at atmospheric pressure, Applied energy, 81: 351-357.

El-Ehwany, A. A.; Hennes, G. M.; Eid, E. I. and El-Kenany, E. A. (2011): Development of the performance of an alpha-type heat engine by using elbow-bend transposed-fluids heat exchanger as a heater and a cooler, Energy conversion and management, 52: 1010-1019.

Le'an, S.; Yuanyang, Z.; Liansheng, L. and Pencheng, S. (2009): Performance of a prototype Stirling domestic refrigerator, Applied thermal engineering, 29: 210-215. 
Hachem, H.; Gheith, R.; Nasrallah, S. B. and Aloui, F. (2015): Impact of operating parameters on beta-type regenerative Stirling machine performances, Proceedings of the ASME-JSME-KSME joint fluids engineering conference.

Tekin, Y. and Ataer, O. E. (2010): Performance of V-type Stirling cycle refrigerator for different working fluids, International journal of refrigeration, 33: 12-18.

Ataer, O. E. and Karabulut, H. (2005): Thermodynamic analysis of the Vtype Stirling cycle refrigerator, International journal of refrigeration, 28: 183-189.

Cheng, C. H.; Huang, C. Y. and Yang, H. S. (2018): Development of a 90-K Beta-type Stirling cooler with rhombic drive mechanism, International journal of refrigeration, DOI: https://doi.org/10.1016/j.ijrefrig.2018.11.027.

Eid, E. I.; Khalaf-Allah, R. A.; Soliman, A. M. and Easa, A. S. (2018): Performance of a beta Stirling refrigerator with tubular evaporator and condenser having -inserted twisted tapes and driven by a solar energy heat engine, Renewable energy: 1-13.

Eid, E. I. and Hennes, G. M. (2002): Analytical study of the performance of a beta type Stirling refrigerator, $10^{\text {th }}$ international conference on applied mechanics and mechanical engineering.

Li, R. and Grosu, L. (2017): Parameter effect analysis for a Stirling cryocooler, International journal of refrigeration, DOI: http://dx.doi.org/doi: 10.1016/j.ijrefrig.2017.05.006.

Batooei, A. and Keshavarz, A. (2018): A gamma type Stirling refrigerator optimization: an experimental and analytical investigation, International journal of refrigeration, 91: 89-100. 


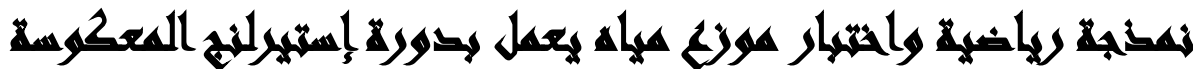

[r]

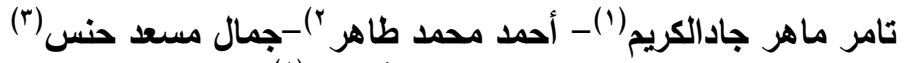

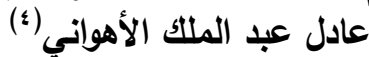 \\ ( ) قسم هندسة القوي الميكانيكية، كلية الهندسة، جامعة عين شمس المانس
}

\begin{abstract}
المستخليف

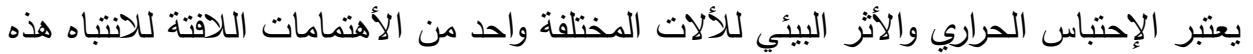

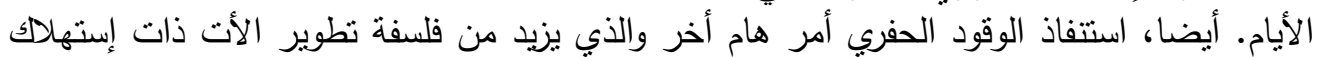

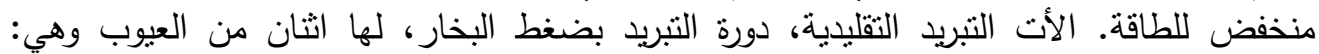

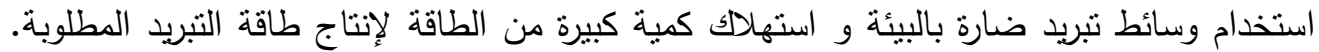

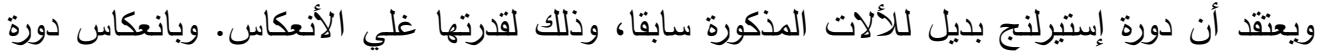

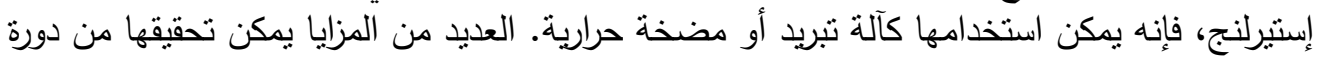

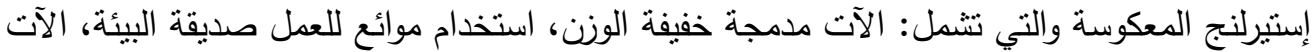

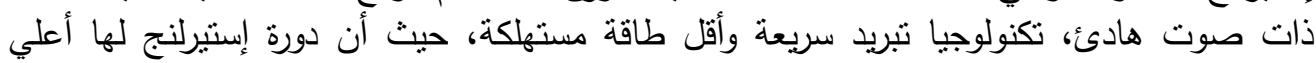

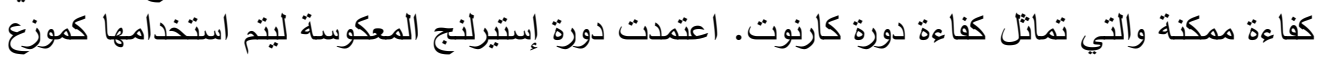

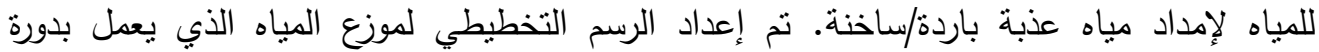

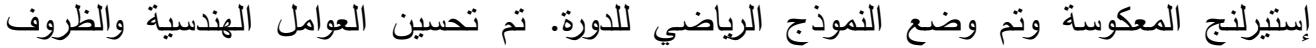
التشغيلية للقيم المثلي لتحقيق درجات حرارة المياه المطلوبة عند الثيات أدني قيمة للطاقة المدخلة والحصول

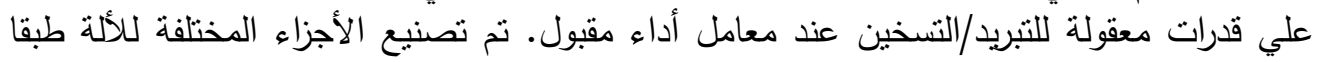
للنتائج النظرية التي تم الحصول عليها وتم تجميع هذه الأجزاء سويا، نم ربط الآلة بمحرك كهربائي

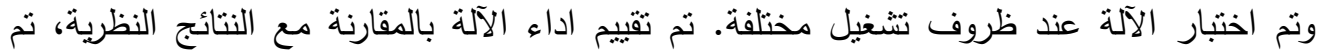
تحقيق قدرات معقولة للتبريد/ التسخين وتم تحقيق درجات حرارة تحت الصفر عند ظروف التهنة اللا حمل.
\end{abstract}

